\title{
AN UNPRECEDENTED HISTORY OF MILITARY AIRCRAFT BIRD STRIKES IN ROMANIA
}

\author{
Valentina-Mariana Manoiu ${ }^{1 *}$, Stefan Gheorghe ${ }^{2}$, Adrian Tiscovschi ${ }^{3}$, \\ Alexandru-loan Craciun ${ }^{4}$,Razvan-Madalin Spiridon ${ }^{5}$ \\ ${ }^{1}$ Assoc. Prof.Dr., Faculty of Geography, University of Bucharest, ROMANIA, \\ valentina.mariana.manoiu@gmail.com \\ ${ }^{2}$ Retired Commander, Head of the Meteorological Department, Romanian Military Aviation \\ Commandment, ROMANIA, gheorghestefan33@gmail.com \\ ${ }^{3}$ Assoc. Prof.Dr., Faculty of Geography, University of Bucharest, ROMANIA, \\ atiscovschi@gmail.com \\ ${ }^{4}$ Environmental Expert, PRO BIODIVERSITAS, ROMANIA, alexandru.ioan.craciun@gmail.com \\ ${ }^{5}$ Environmental Consultant, Auditeco GES, ROMANIA, razvanspiridon@gmail.com \\ ${ }^{*}$ Corresponding author
}

\begin{abstract}
This paper tackles a never-before-approached topic in Romania, as it aims to empirically analyse the 26 cases of collision between military aircrafts and birds that occurred between 1967 and 1991. The work is based exclusively on observations made by the Head of the Meteorological Department of the Romanian Military Aviation Commandment between 1990 and 1993, commander (retired) and meteorologist. This paper complements various scientific and statistical studies in the field, which lacked information about military aircraft bird strikes in Romania. In addition to these 26 collisions, 3 other incidents involving military aircrafts may have been bird-related. They occurred in 2002 (2, one of which was a catastrophe that lead to the pilot's death) and 2007 ( 1 incident). The study objectives were to analyse the collisions' locations (prevalence of certain aerodromes), the atmospheric and seasonal conditions in which the collisions occurred, and the types of aircrafts and bird species involved in the incidents, which resulted in a map of the analyses' main elements. In terms of results and conclusions, it was found that in Romania, in the analysed period, most of the collisions occurred in areas where aerodromes were located in the vicinity of water sources, in autumn, followed by spring, which is linked to the birds' migration activity, as well as to agricultural practices, as birds relocate in order to look for food sources. Most collisions occurred during the day, under normal meteorological conditions, up to altitudes of 400-500 m. It was also noticed that in over $50 \%$ of cases collisions occurred in the vicinity of aerodromes, most often during landing. The most important element that favours bird presence near aerodromes is food and water source availability, which is followed by the availability of various nesting-suitable locations. This study also touches on flight ornithological insurance, factors that stimulate bird concentration near aerodromes, recommendations for ensuring flight safety from an ornithological perspective, as well as methods used to hinder bird presence near aerodromes.
\end{abstract}

Keywords: military aircraft bird strikes, Romania, flight safety, ornithological insurance 


\section{INTRODUCTION}

Bird strikes are one of the main causes of accidents involving aircrafts worldwide, in both civil and military aviation (Gheorghe, 1990, pp. 232-240; Richardson, 1996, pp. 33-56; Richardson and West, 2000, pp. 6797; Sodhi, 2002, pp. 587-595; Dekker and Van Gasteren, 2005; Zakrajsek and Bissonette, 2005, pp. 258264; Kitowski, 2011, pp. 183-191).

Military aircrafts are more vulnerable to bird strikes than civil aircrafts (Sodhi, 2002, pp. 587-595) because they fly at high speeds even at low altitudes $(30-300 \mathrm{~m})$, i.e. where birds fly. Approximately $54 \%$ of bird strikes on military aircrafts worldwide occur on aerodrome premises or in the immediate vicinity (take-off or landing) (Sodhi, 2002, pp. 587-595).

With regard to Romanian military aviation, its development, combat action range, as well as the high flight diapason and speed require crew members to know all phenomena that may pose a threat to the flight, including bird-aircraft strike hazards (Gheorghe, 1990, pp. 232-240). The present paper, a first in Romania, aims to empirically analyse the 26 cases of collisions between military aircrafts and birds that occurred between 1967 and 1991. The paper is based exclusively on observations made by the Head of the Meteorology Department of the Romanian Military Aviation Commandment (1990-1993), commander (retired) and meteorological engineer. This paper complements various scientific and statistical studies that lacked information about military aircraft bird strikes in Romania.

In addition to the 26 collisions between military aircrafts and birds, 3 more incidents involving military aircrafts may have been caused bird impacts. They occurred in 2002 ( 2 accidents, one of which was a catastrophe and resulted in the pilot's death) and 2007 (1 accident).

Using the available information, the study objectives were to analyse the collisions' locations (dominance of certain aerodromes), atmospheric and seasonal conditions in which the collisions occurred, the types of aircrafts and species of birds involved, and mapped the main elements of the analysis.

\section{ANALYSIS OF MILITARY AIRCRAFT BIRD STRIKES IN ROMANIA - RESULTS AND DISCUSSIONS}

In Romania, between 1967 and 1991, there were 26 military bird strikes, listed in the table below (Table 1):

Table 1. Military aircraft bird strikes recorded between 1967 and 1991 in Romanian air space (Observations made by the Head of the Meteorology Department of the Romanian Military Aviation Commandment)

\begin{tabular}{|l|l|l|l|}
\hline & Date & Type of aircraft & Aerodrome \\
\hline 1. & 26.09 .1967 & MIG 19 & Borcea \\
\hline 2. & 21.01 .1976 & MIG 21 & Borcea \\
\hline 3. & 07.09 .1976 & MIG 21 & ATC (Aviation Training Center) Bacau \\
\hline 4. & 26.07 .1977 & MIG 21 & Mihail Kogalniceanu \\
\hline 5. & 08.09 .1977 & MIG 21 & Mihail Kogalniceanu - catastrophe \\
\hline 6. & 14.04 .1979 & MIG 21 & Giarmata \\
\hline 7. & 19.07 .1979 & MIG 21 & Borcea \\
\hline 8. & 07.08 .1979 & MIG 21 & Giarmata \\
\hline 9. & 28.08 .1979 & MIG 21 & Mihail Kogalniceanu \\
\hline 10. & 28.08 .1979 & MIG 21 & Borcea \\
\hline 11. & 03.09 .1979 & MIG 21 & ATC Bacau \\
\hline 12. & 04.09 .1979 & MIG 21 & Mihail Kogalniceanu \\
\hline 13. & 06.09 .1979 & MIG 21 & Borcea \\
\hline 14. & 21.09 .1981 & IAR 316 & Otopeni \\
\hline 15. & 18.02 .1982 & MIG 21 & Borcea \\
\hline 16. & 12.08 .1983 & MIG 21 & Mihail Kogalniceanu \\
\hline 17. & 06.09 .1983 & MIG 21 & Borcea \\
\hline 18. & 29.03 .1984 & MIG 23 & Mihail Kogalniceanu \\
\hline 19. & 07.06 .1984 & MIG 21 & Mihail Kogalniceanu \\
\hline 20. & 04.05 .1988 & MIG 21 & ATC Bacau - catastrophe \\
\hline 21. & 06.09 .1989 & MIG 21 & Borcea \\
\hline 22. & 07.09 .1989 & MIG 21 & Campia Turzii \\
\hline 23. & 03.04 .1990 & L 29 & Boboc \\
\hline & & & \\
\hline
\end{tabular}


IJASOS- International E-Journal of Advances in Social Sciences, Vol. IV, Issue 10, April 2018

\begin{tabular}{|l|l|l|l|}
\hline 24. & 18.12 .1990 & MI 8 & Alexeni \\
\hline 25. & 10.09 .1991 & MIG 21 & Borcea \\
\hline 26. & 09.10 .1991 & MIG 21 & Giarmata \\
\hline
\end{tabular}

9 incidents occurred at the Borcea aerodrome, 7 at the Mihail Kogalniceanu aerodrome, 3 at ATC (Aviation Training Center) Bacau, 3 at Giarmata aerodrome, 1 at Otopeni, 1 in Campia Turzii, 1 at Alexeni, and 1 at Boboc aerodrome. MIG aircrafts (1 MIG 19, 21 MIG 21 and 1 MIG 23) were involved in 23 military aircraft bird strikes, while in the remaining 3 cases other types of aircrafts were identified (1 IAR 316, $1 \mathrm{~L} 29$ and 1 MI 8).

Temporally, 1 accident occurred in 1967, 2 in 1976, 2 in 1977, 8 in 1979, 1 in 1981, 1 in 1982, 2 in 1983, 2 in 1984, 1 in 1988, 2 in 1989, 2 in 1990, and 2 in 1991. Regarding the months of occurrence, 1 incident was recorded in January, 1 in February, 1 in March, 2 in April, 1 in May, 1 in June, 2 in July, 4 in August, 11 in September, 1 in October, and 1 in December. Seasonally, 4 collisions occurred in spring, 7 in summer, 12 in autumn, and 3 in winter.

It is important to note that all aforementioned aerodromes are located close to water bodies with rich avifauna. The most complex ecosystems are located in the vicinity of Borcea and Mihail Kogalniceanu aerodromes, where the highest numbers of accidents occurred. Ornithological specificities of these two aerodromes will be described in this chapter.

In addition to these 26 bird strikes recorded by the former Head of the Meteorology Department of the Romanian Military Aviation Commandment, after the year 2000, 3 more accidents involving birds occurred, 2 in 2002 (February and October) and 1 in 2007 (October).

On 21 February 2002, a MIG 21 Lancer aircraft, from Feteşti (Borcea) Air Base 86, crashed in lezer fishing lake during a training flight, in the vicinity of Călăraşi City. The plane was destroyed, and the pilot lost his life. On 23 October 2002, a MIG 21 Lancer crashed from an altitude of $30 \mathrm{~m}$ during a training flight at the end of the take-off runway of the Bacău Aviation Unit aerodrome. The pilot managed to catapult from the aircraft before impact. On 30 October 2007, a MIG 21 Lancer of the Campia Turzii Airbase no. 71 was involved in an aviation accident, which resulted in broken dome following an impact with several birds. The pilot managed to land the aircraft.

The most difficult element in analysing such collisions is identifying the bird species that caused the accidents. In some instances, the pilots and aerodrome staff reported that the aircrafts were red following the impact with a large number of small birds, which made it impossible to identify the bird species.

Identifying the bird species is possible when the engine air shaft sucks in a medium or large-sized bird, e.g. the catastrophe dated 8 September 1977, at the Mihail Kogalniceanu aerodrome, when two seagulls got caught in aircraft's system during take-off at an altitude of about 300-400 m, when the pilot could not catapult, or the landing catastrophe dated 4 May 1988 at the Bacau aerodrome, which resulted in the pilot's death, when the bird was a stork. Unfortunately, in such collisions with large birds, there is a very high risk that pilots cannot save their lives.

In such analyses, based on knowing the bird species that are present in the vicinity of aerodromes, we can note which species are most likely to be involved in aircraft collisions.

Of the 9 incidents recorded at Borcea Aerodrome, 5 occurred in September, the first month of autumn. Ornithologically, this is a complex season, as this is when young birds train to fly and when the autumn migration begins. At the same time, in September birds have an abundant food supply, as agricultural land is a rich food source, and there are numerous flights to and from such auspicious locations. Borcea Aerodrome is located near the Danube and the ROSPA0012 Borcea Arm Natura 2000 site (Romanian Ministry of Environment site), with an area of 13,096.8 hectares, in lalomița and Călărași counties.

The area is very important as a waterfowl habitat, sheltering bird populations during the breeding season, as well as Nordic populations that fly in during fall passage or wintertime. 34 bird species of conservation interest at European level were identified at the site (Romanian Ministry of Environment site), which is used during fall passage as a feeding and resting place by numerous specimens of black stork (Ciconia nigra), white stork (Ciconia ciconia), glossy ibis (Plegadis falcinellus), common tern (Sterna hirundo), whiskered tern (Chlidonias hybridus), little tern (Sterna albifrons), black tern (Chlidonias niger), black-winged stilt (Himantopus himantopus), pied avocet (Recurvirostra avosetta), wood sandpiper (Tringa glareola), and many species of ducks (Anas querquedula, A. clypeata, A. acuta) (Romanian Ministry of Environment site). In winter, both wetlands and agricultural areas within site limits or in its immediate vicinity are highly important feeding and resting habitats for up to 7,000 red-breasted geese (Branta ruficollis) (Romanian Ministry of Environment site). Moreover, this is a wintering area for a large number of pygmy cormorants 
(Phalacrocorax pygmeus), but also for up to 30,000 greater white-fronted geese (Anser albifrons) (Romanian Ministry of Environment site).

Another aerodrome with a high number of military aircraft bird strikes (7, of which 4 recorded in August and September) is Mihail Kogalniceanu, located in Constanta County, in Dobrogea. Dobrogea is crossed by numerous bird migration routes (Radu, 1984, pp. 96-100; pp. 176-210). Generally, birds migrate at heights that range 100 to $1,000 \mathrm{~m}$, but large bird species can fly as high as 1,200-1,500 m (Radu, 1984, pp. 96-100; pp. 176-210). A higher migratory density was found between 100-200 m.

When planning and executing military aircraft flights at the Mihail Kogalniceanu aerodrome, seasonal ornithological specificities must also be taken into account. Ornithologically, winter is the most stable season. Birds that winter in our country are active during the day; they fly to and from feeding places at heights that range between 20 and $50 \mathrm{~m}$, or 300-500 m in some cases (Radu, 1984, pp. 96-100; pp. 176-210). Spring is a complex season ornithologically. This is when an intensive movement starts from wintering to nesting areas. The season's main migration direction is from $\mathrm{S}$ and $\mathrm{SW}$ to $\mathrm{N}$ and NE, at heights of 1,000-1,500 m (Radu, 1984, pp. 96-100; pp. 176-210). Summer is divided into two periods: early summer (15.05-30.07), when most birds arrive, and late summer (30.07-15.09), when the new generation of birds starts flying. In autumn, young birds train to fly and migration begins. Migration takes place along a S-SE direction at heights that range from 2,000 to 3,000 m (Radu, 1984, pp. 96-100; pp. 176-210).

In the Mihail Kogalniceanu aerodrome area there is rich avifauna, which is divided into two categories: migratory birds - pelicans, storks, cranes, cormorants, herons, ducks, geese, swallows, etc; non-migratory birds - seagulls, starlings, crows, wild pigeons, sparrows, etc. Migration from the south to nesting areas in the Danube Delta occurs in late March, when storks and swallows begin to appear. Towards the end of April, the other species migrate, e.g. cormorants, herons, ducks, geese, etc. (Radu, 1984, pp. 96-100; pp. 176210). Bird migration to the south begins approximately in October, and towards the end of November some species arrive from northern Europe in the marine area and ponds with a milder climate; some of them, such as ducks, geese, coots, stay until January, after which they continue their migration to the south (Radu, 1984, pp. 96-100; pp. 176-210). During their time in Dobrogea, bird flocks move locally on a daily basis, during the day from the sea, lakes and forests to agricultural lands, looking for food, and vice versa at night at heights of $0-100 \mathrm{~m}$.

So far, from the observations and analyses on collisions between military aircrafts and birds, it can be concluded that seagulls, starlings and storks are the birds that most frequently caused such incidents.

From the military aircraft bird strikes analysed so far, it was found that the impact force is proportional to the aircraft's squared flight speed. With low-speed airplanes, the pilot can avoid a collision with birds by making certain manoeuvres to avoid impact, while with high-speed aircrafts, these manoeuvres are impossible (Gheorghe, 1990, pp. 232-240). Such impacts result in: punctures and deformations of the aircrafts' cover and fuselage; damage or destruction of the cabin's windscreen; compressor blade deformation or damage. Upon analysis of the recorded incidents, it was concluded that most collisions occur during the day, under normal weather conditions, up to heights of $400-500 \mathrm{~m}$. It was also found that in more than $50 \%$ of cases, collisions occur close to aerodromes, during take-off, runway lap and landing (Gheorghe, 1990, pp. 232240). This chapter's main elements are rendered graphically in the Fig. 1.

\section{ORNITHOLOGICAL ASSURANCE OF MILITARY AIRCRAFT FLIGHTS IN ROMANIA}

Due to the collisions recorded between military aircrafts and birds, the set of measures for flight safety also includes ornithological assurance (Gheorghe, 1990, pp. 232-240). Planning ornithological flight assurance measures to prevent such collisions is the military unit leadership's responsibility, while execution is carried out by the flight crew. The information is passed on to the leadership by the meteorology officer on duty during the flight's planning, preparation and execution stages (Gheorghe, 1990, pp. 232-240).

Ornithological flight assurance entails (Gheorghe, 1990, pp. 232-240): visual inspection; on-site bird observations at the aerodrome using radiolocation technology; collecting, processing and analysing ornithological data; ornithological prediction for each flight preparation and operation stage; developing and applying bird control measures, and eliminating factors that attract birds to the aerodrome; informing the unit's leadership, flight leader and crew about the current and future ornithological status of the aerodrome area and flight routes; analysing impact occurrences.

The determination of ornithological conditions in the flight area is performed by the meteorological research unit or by transportation aircraft and helicopter crew members. Ornithologically, flight safety must be ensured first and foremost in aerodrome districts. Where the surrounding areas have certain specificities, birds are more active during flight activities. The factors that stimulate bird concentration near aerodromes are: grains 
and other cereals, plots of vegetables, orchards and vineyards, where birds find both feeding and resting areas; household waste generated by aerodrome staff, which must be managed carefully so that it does not become an avifauna polarization source in the aerodrome area; forests, waters, marshes and villages, where species that fly near the runway several times a day looking for food can nest.

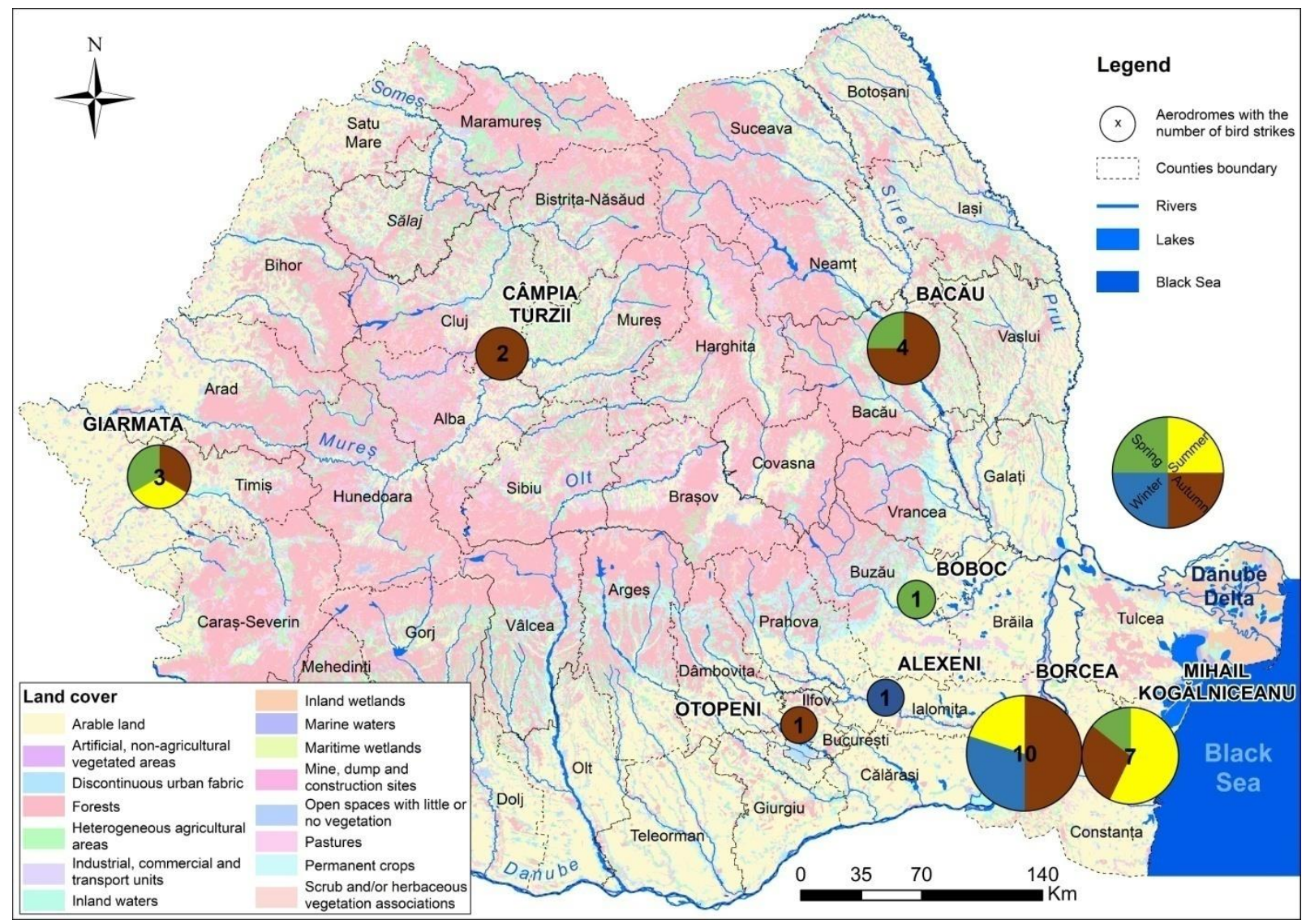

Fig. 1. The military bird strikes in Romania, between 1967 and 2007, represented on the land cover map (based on Corine Land Cover, 2012)

As a result, certain measures are taken to limit the number of birds in the aerodrome area. At present, the following acoustic and optical means are used to chase birds from aerodrome premises in Romania: noise from various devices, hunting rifles, mechanical human silhouettes, ratchets, transmitting alarming bird chirping recordings via loudspeakers, shining dye applied onto radiolocation station antennae, light rockets and other signalling (Gheorghe, 1990, pp. 232-240).

When studying and assessing the ornithological status, the periodicity of annual bird - migratory and nonmigratory species - activity must be taken into account. The aerodrome location's physico-geographical particularities and stationary periods are also to be considered. At the same time, the assessment of the ornithological status must be correlated with the evolution of weather conditions. The recorded observations indicate that bird flight intensity, especially of migratory birds, is low during precipitation, fog, low cloud cover (50-150 $\mathrm{m})$ and strong winds. Also, a sudden decrease in air temperature can halt spring migration and, in autumn, speed up the birds' flight from north to south (Gheorghe, 1990, pp. 232-240).

In order to ensure flight safety, from the ornithological perspective, it is advisable: before flying, to study and establish the ornithological conditions in the aerodrome area in order to exclude the possibility of aircrafts colliding with birds; to ensure a thorough surveillance of airspace, both at low and high altitudes $(7-8 \mathrm{~km})$, as large birds can fly in, especially during summer; to ignite dashboard light signalling, especially during take-off and landing, in order to chase away birds from the aircraft trajectory; with the flight manager's approval, to change the flight echelon (when birds are encountered) by rising to a higher altitude, so that the birds remain below or to the side; to provide the crew with information on bird occurrences and changes in ornithological conditions; to reduce speed in high bird concentration areas, as the likelihood of collision decreases (Gheorghe, 1990, pp. 232-240). This is a complex process that depends not only on organizational measures, but also on how commanders and flight crew members act. 


\section{CONCLUSIONS}

The analysis indicates that, in Romania, the number of collisions between military aircrafts and birds has decreased significantly recently. Thus, while between 1967 and 1991 there were 26 military aircraft bird strikes, from 1992 to 2016 only 3 such incidents occurred. The birds that most frequently caused collisions were seagulls, starlings and storks, and the aerodromes with the most complex ornithological statuses are the ones in Borcea and Mihail Kogalniceanu. The highest number of accidents caused by birds (eight) was 1979, and autumn was the season with the most recorded military aircraft bird strikes.

To conclude, ornithological assurance in military aviation is an important contributor to the safety of training flights, and transportation and combat activities, by providing commanders and crew members with ornithological data, necessary for planning and conducting flight operations, as well as by timely briefing combat crews at command points and flight manager on the ornithological status and conditions in flight sectors.

\section{REFERENCE LIST}

Dekker, A., Van Gasteren, H. (2005). Eurbase: Military Bird Strike Frequency in Europe. IBSC27 Proceedings/WP IX-5, Athens.

Gheorghe, S. (1990). Meteorologie pentru piloţi (Meteorology for Pilots). Ministerul Apararii Nationale, Comandamentul Aviatiei Militare, Bucuresti, Romania, pp 232-240.

Kitowski, I. (2011). Civil and Military Birdstrikes in Europe: An Ornithological Approach. Journal of Applied Sciences. Asian Network for Scientific Information, vol. 11, pp 183-191.

Radu, D. (1984). Pasarile in peisajele Romaniei (Birds in the Romanian Landscapes). Editura Sport-Turism. Bucuresti, Romania, pp 96-100/pp 176-210.

Richardson, J.W. (1996). Serious Birdstrike-Related Accidents to Military Aircraft of Europe and Israel: List and Analysis of Circumstances. International Bird Strike Committee Proceedings and Papers 23 (London, U.K.), pp 33-56.

Richardson, J. W., West, T. (2000). Serious Birdstrike Accidents to Military Aircraft: Updated List and Summary. IBSC (International Bird Strike Committee) Proceedings: Papers \&Abstr. 25 (Amsterdam, vol. 1), pp 67-97.

Romanian Ministry of Environment. Scientific Information on Natura 2000 ROSPA0012 Borcea Arm SPA Site, http://biodiversitate.mmediu.ro/rio/natura2000/view?doc_id=ROSPA0012

Sodhi, N.S. (2002). Competition in the Air: Birds versus Aircraft, The Auk 119 (3). The American Ornithologists' Union, pp 587-595.

Zakrajsek, E.J., Bissonette, J.A. (2005). Ranking the risk of wildlife species hazardous to military aircraft. Wildlife Society Bulletin 33(1), USA, pp 258-264.

*** Corine Land Cover 2012, http://land.copernicus.eu/pan-european/corine-land-cover/clc-2012 